\title{
Receiver function imaging in strongly laterally heterogeneous crust: Synthetic modeling of BOLIVAR data*
}

\author{
Yongbo Zhai" and A. Levander \\ Department of Earth Science, Center for Computational Geophysics, Rice University, \\ Houston, TX 77005, USA
}

\begin{abstract}
We resolve a large $(\sim 20 \mathrm{~km})$ discrepancy in Moho depth determined from PdS receiver functions (RFs) and from active source seismic profiling in the complex Caribbean-South American plate boundary zone in eastern Venezuela. As part of the BOLIVAR experiment 20 broadband stations were deployed along an active source profile to record teleseisms. Using the extremely heterogeneous crustal model obtained from active source data, we generated 2D finite-difference elastic wave synthetics and from them calculated receiver functions and CCP stacks. We compare the observations with synthetic sections that have been spatially sampled at $0.25 \mathrm{~km}$ to $40 \mathrm{~km}$. The densely sampled synthetics show that several events in the field data that were originally interpreted as the Moho are multiple reflections within sedimentary basins. Where the Moho has the steepest dip under the plate boundary the CCP stacks fail to image the Moho well, regardless of the density of spatial sampling. A suitable spatial sampling criterion for clearly imaging the lower crust and Moho is to overlap Fresnel zones by $50 \%$ at Moho depth, which for the $1 \mathrm{~Hz}$ receiver functions examined here, requires an instrument spacing of $15-20 \mathrm{~km}$, with the actual field data density ranging from $20 \mathrm{~km}$ to $100 \mathrm{~km}$.
\end{abstract}

Key words: receiver function; CCP stacking; finite-difference modeling; BOLIVAR project; Fresnel zone

CLC number: P315.2 Document code: A

\section{Introduction}

Receiver function imaging is an increasingly common means to estimate the depth to the Moho and other interfaces in the crust, as well as those in the upper mantle (Ammon, 1991; Langston, 1977; Niu et al., 2005; Owens et al., 1984). However, most receiver function depth estimates for the Moho are based on traveltime corrections at a single station, common conversion point (CCP) stacking (Dueker and Sheehan, 1997; Zhu, 2000) or $H-\kappa$ analysis (Zhu and Kanamori, 2000), generally utilizing a layered medium assumption for calculating interface depths from the ray equations. In this study we examine the reliability of such estimates by generating synthetic seismograms for a complex crustal structure derived from an active source profile in the

\footnotetext{
* Received 23 October 2010; accepted in revised form 7 January 2011; published 10 February 2011.

+ Corresponding author. e-mail: yz4@rice.edu

(C) The Seismological Society of China and Springer-Verlag Berlin Heidelberg 2011
}

southern Caribbean plate boundary, for comparison to teleseismic seismograms made along the same profile.

The BOLIVAR (Broadband Ocean-Land Investigations of Venezuela and the Antilles arc Region) project is a multi-disciplinary investigation of the lithosphere and deeper structures associated with the diffuse Caribbean (CAR)-South America (SA) plate boundary zone (Bezada et al., 2010; Clark et al., 2008; Levander et al., 2006; Niu et al., 2007). The active source profile "64W" is a $460-\mathrm{km}$ long, NNW-SSE transect across the east-west striking CAR-SA plate boundary zone at $64^{\circ} \mathrm{W}$, consisting of 33 ocean bottom seismometers (OBS) and 344 REFTEK-125 Texan land seismographs, recording 7500 marine airgun shots and two explosive landshots (Clark et al., 2008). Additionally, the BOLIVAR project included a deployment of $\sim 55$ portable broadband land and OBS seismograph stations and data from the 38 stations of Venezuela national seismograph network. About 20 of these stations lie along or near to the $64 \mathrm{~W}$ active source profile but extended both further to the south and to the north (Figure 1a). 


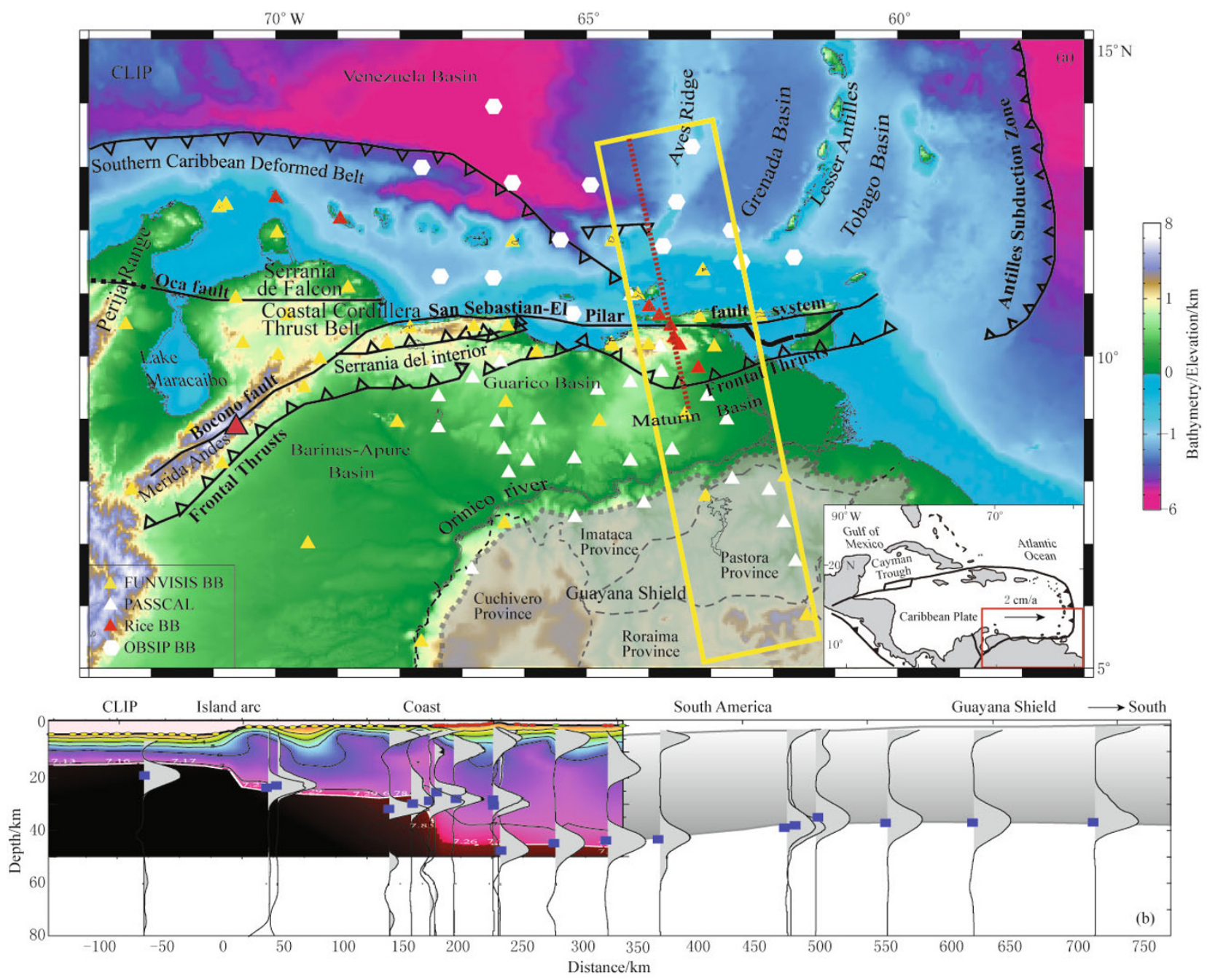

Figure 1 Elevation/bathymetry map of the BOLIVAR study area in Northeast South America (a, modified from Niu et al., 2007), and "64W" $\mathrm{P}$ wave velocity profile superimposed by passive source receiver functions (b, modified from Clark et al., 2008 and Niu et al., 2007). Principal plate boundary fault systems and geologic provinces are marked. CLIP: Caribbean Large Igneous Province. Yellow box indicates the location of "64W" profile (Levander et al., 2006); red dashed line is the active source line. Inset shows the Caribbean Plate and surrounding area. Black arrow indicates its present motion direction in a fixed South America Plate frame. Note that there exists a discrepancy of Moho depth at model coordinate of 150-225 km between Clark's model (colored background model in b) and that predicted by receiver function stacks (blue bars).

Clark et al. (2008) developed a 2D seismic P-wave velocity model inverting first arrival and Moho wideangle reflection travel times (Zelt and Smith, 1992) from the active source data. This profile has large lateral and vertical velocity variations at all levels, particularly in the $\sim 350 \mathrm{~km}$ wide Caribbean-South American plate boundary zone. The crust thickens by more than a factor of 2 crossing from the Caribbean Plate (Moho depth $\sim 20 \mathrm{~km}$ ) into a fold and thrust belt on the northern edge of the South American continent (Moho depth $\sim 50 \mathrm{~km}$ ). The upper crustal structure along the profile is complicated by deep, $>10 \mathrm{~km}$, irregular sedimentary basins both onshore and offshore in the plate boundary zone.

Niu et al. (2007) used the teleseismic data recorded by BOLIVAR project to estimate crustal thickness of southeastern Caribbean plate boundary with PdS receiver functions (RF) from $H-\kappa$ analysis. Although the Moho depth determined from the receiver functions agrees well with the estimates of active source velocity model in the flat cratonic structure south of the coastal mountains, discrepancies of up to $20 \mathrm{~km}$ between Moho estimates from the RFs and the active source model appear in the complicated CAR-SA plate boundary zone 
(Figure 1b). In this study, we generated synthetic PdS receiver functions based on the active source model and applied the common conversion point (CCP) stacking technique (Dueker and Sheehan, 1997; Zhu, 2000) to examine the reason for the difference between the Moho depths determined from the PdS receiver functions and the active source model in the plate boundary zone.

\section{Finite-difference modeling}

We first calculated the $2 \mathrm{D}$ elastic synthetic seismograms using a 2nd-order staggered grid finite-difference (FD) scheme, which requires less storage and provides more accuracy for media with a wide range of Poisson ratios than non-staggered grids (Levander, 1988; Luo and Schuster, 1990). We adopted the compressional wave velocity model (Clark et al., 2008) as the reference, and modified it to meet the requirements of forward modeling in the following ways: We linearly interpolated the model to a uniform grid size of $0.25 \mathrm{~km}$. For a 2nd-order FD scheme, 10 grids per wavelength are required to minimize grid dispersion:

$$
f_{\max }=\frac{C_{\min }}{n \times h}
$$

where $f_{\max }$ is the maximum frequency of the signal, $C_{\text {min }}$ is the minimum velocity of the model, $n=10$ for the 2nd-order FD simulation, $h$ is the grid size. For a desired frequency the grid size is proportional to the minimum velocity of the model. In the next step, therefore, we replaced velocities $<4 \mathrm{~km} / \mathrm{s}$ with $4 \mathrm{~km} / \mathrm{s}$, which is the velocity at the bottom of sedimentary basin, to reduce the computational cost. This will keep the shape of the basin bottom but eliminate the water layer $\left(v_{\mathrm{P}}=1.5\right.$ $\mathrm{km} / \mathrm{s}$ ), so that the shear wave is recorded by stations at the surface. Since Clark et al. only determined compressional wave velocity, we used the empirical relations between $v_{\mathrm{P}}, v_{\mathrm{S}}$ and density (Brocher, 2005) to generate shear wave velocity and density models. The original $\mathrm{P}$ wave velocity model of Clark et al. and our modified $\mathrm{P}$, $\mathrm{S}$ and density models are shown in Figure 2. Note that the models are extrapolated in both horizontal and
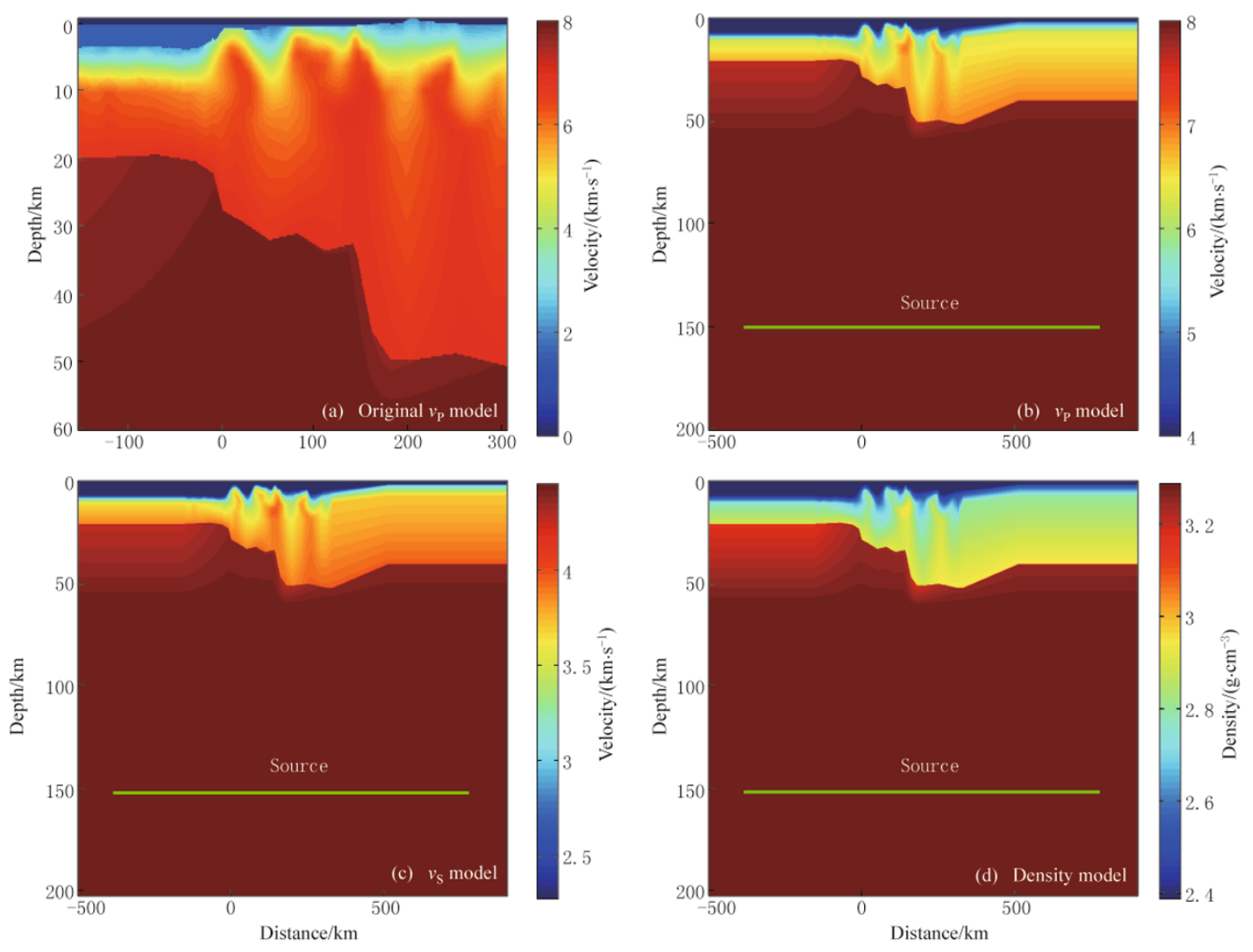

Figure 2 (a) Original P wave velocity model (Clark et al., 2008); (b) Modified P velocity model; (c) S velocity model; (d) Density model. Planar P waves were inserted at $150 \mathrm{~km}$ depth in the mantle with incidence angles of $\pm 10, \pm 20$, and \pm 30 degrees in successive finite-difference simulations. See context for details. 
vertical directions for simulation convenience. The final models (Figures 2b, 2c, 2d) are $1400 \mathrm{~km}$ horizontally (from $-500 \mathrm{~km}$ offshore to $900 \mathrm{~km}$ onshore) and $201 \mathrm{~km}$ vertically (from $1 \mathrm{~km}$ above the sea level to $200 \mathrm{~km}$ in the mantle).

To start the simulation, we inserted a planar $\mathrm{P}$ wave source at depth of $150 \mathrm{~km}$ with center frequency of $\sim 0.41 \mathrm{~Hz}$ and maximum frequency of $\sim 1 \mathrm{~Hz}$. We simulated six events with incident angles of $\pm 10, \pm 20$, and \pm 30 degrees, corresponding to epicentral distances of earthquakes at $\sim 98^{\circ}, 87^{\circ}$, and $58^{\circ}$ for a source at the surface (note that in practice we avoid using data at epicentral distance $>95^{\circ}$, because of contaminating core phases). We saved the seismograms at every grid points on the surface $\left(d_{x}=0.25 \mathrm{~km}\right)$ sampled at $0.2 \mathrm{sec}-$

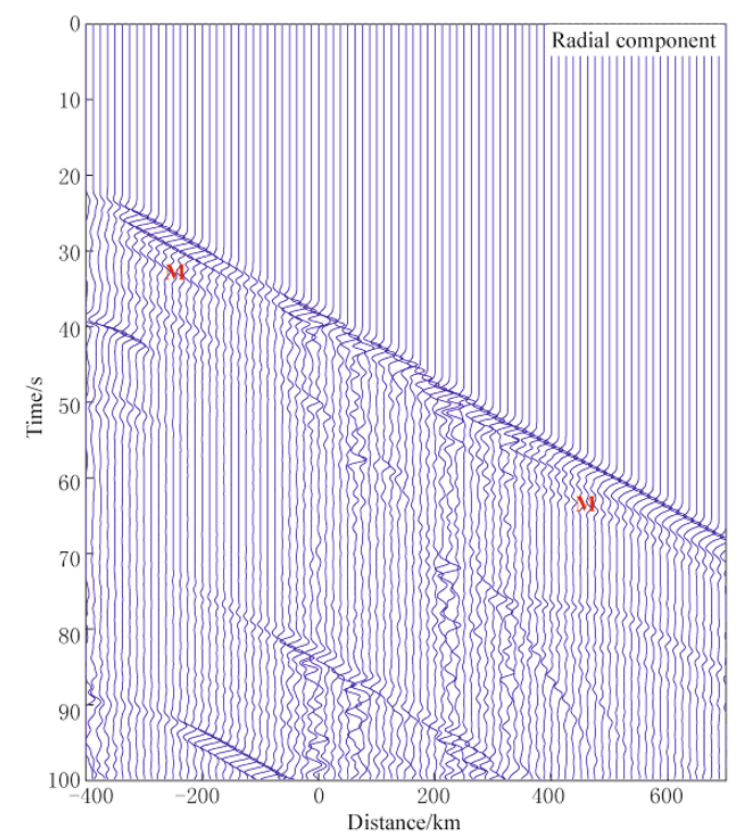

ond. The total computational time is 100 seconds, long enough to record all conversions within the crust and uppermost mantle along with their multiple reflections. We set the time increment at three fourths of the stability limit:

$$
\Delta t=0.75 \times \frac{h}{\sqrt{n} C_{\max }},
$$

where $\Delta t$ is the time increment of the step, $h$ is the grid size, $n$ is the number of dimensions, $C_{\max }$ is the maximum velocity of the model, $8.0 \mathrm{~km} / \mathrm{s}$. Figure 3 shows a common source gather of radial and vertical component seismograms for an event with an incidence angle of 20 degrees. Figure 4 shows the snapshot of the wavefield for the same event at 35 seconds.

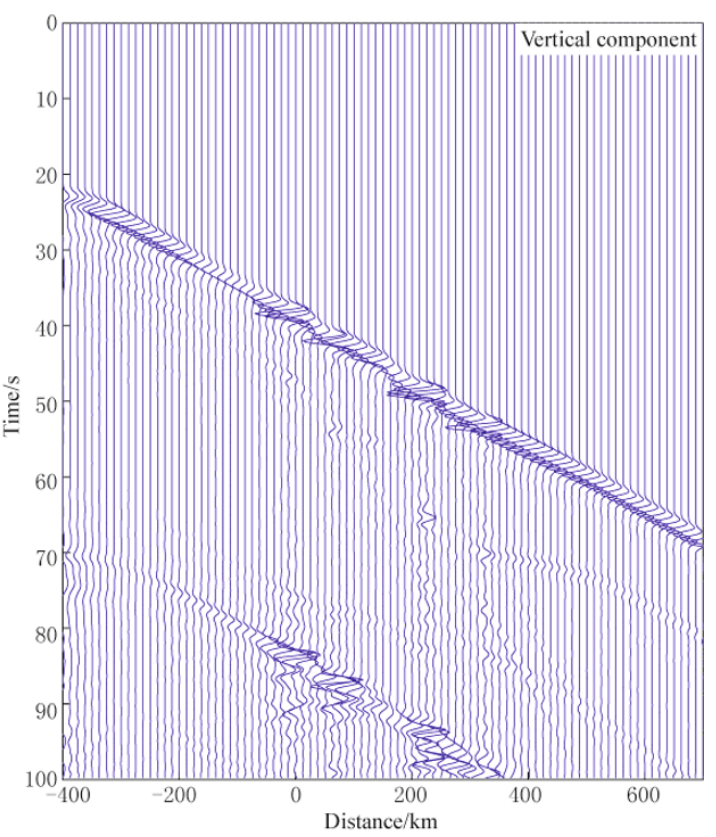

Figure 3 Radial (left) and vertical (right) component seismograms for the event at $20^{\circ}$. "M" marks the conversion from the Moho. Note that the amplitudes of the seismograms are amplified by a factor of 20 , and every 40 traces are plotted for visualization purpose.
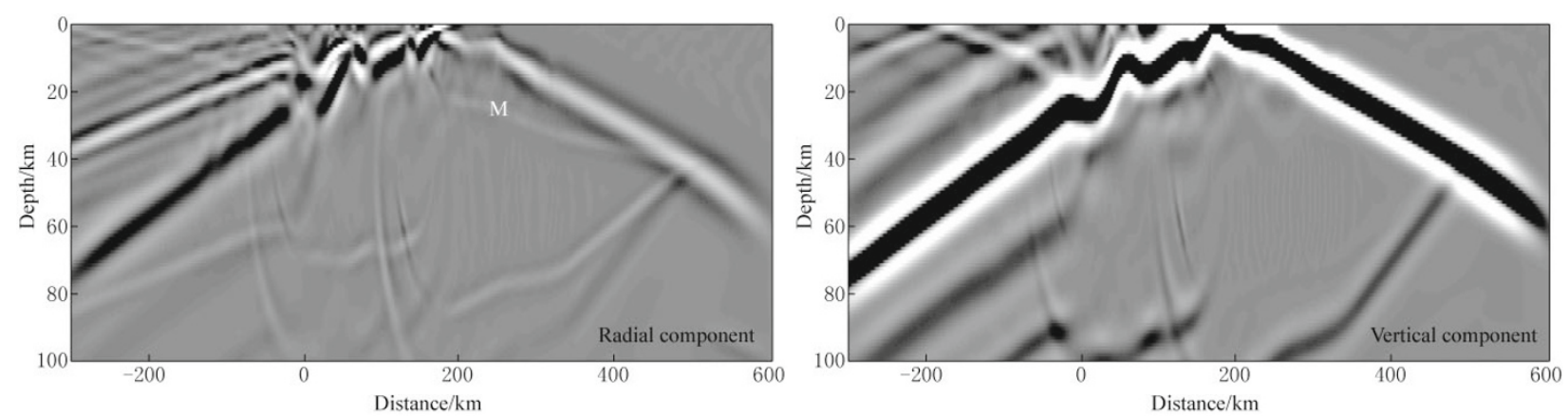

Figure 4 Snapshots at 35 seconds for the event at $20^{\circ}$. "M" marks the conversion from the Moho. 


\section{Synthetic receiver functions}

When a planar $\mathrm{P}$ wave propagates in layered homogeneous media, it will generate P-to-S converted wave and surface reverberations at horizontal discontinuities. Figure 5 shows the corresponding ray paths. The P-to-S conversion at the Moho is indicated by "M" in Figures 3, 4 and 6. At teleseismic distances, the incident angle is small, $\mathrm{P}$ waves are recorded predominantly on the vertical component, with $\mathrm{S}$ waves recorded predominantly on the radial component. Therefore one can simply deconvolve the vertical component seismogram from the radial component seismogram to remove the source and path effects, ending up with the PdS receiver function (Ammon, 1991). The PdS RF is just a scaled version of the radial component seismogram with the earthquake source time function and $\mathrm{P}$ multiples removed, representing the structural response to incoming P-waves beneath the receiver. The deconvolution can be achieved either in the frequency domain or in the time domain (Ligorria and Ammon, 1999). Here we applied the "water-level" method in frequency domain (Ammon, 1991; Clayton and Wiggins, 1976; Niu et al., 2007), which fills spectral "holes" of the denominator while taking the division. The receiver function can then be written as

$$
E_{\mathrm{RF}}(\omega)=\frac{R(\omega)}{Z(\omega)}=\frac{R(\omega) Z^{*}(\omega)}{\phi(\omega)} G(\omega),
$$

where $\phi(\omega)=\max \left\{Z(\omega) Z^{*}(\omega), l \max \left[Z(\omega) Z^{*}(\omega)\right]\right\}, l$ is the "water level" representing the minimum amplitude allowed in the denominator to stabilize the division, and $G(\omega)$ is the Gaussian filter used as a low-pass filter:

$$
G(\omega)=\exp \left(\frac{-\omega^{2}}{4 a^{2}}\right)
$$

where $a$ is the "Gaussian width" that controls the pulse width and high corner frequency in the resulting receiver function. In this study we used $c=0.01$ and $a=2.0$. The receiver function is then obtained by inverse-Fourier transforming $E_{\mathrm{RF}}(\omega)$ into the time domain. Figure 6 shows a common source receiver function gather of the event with incident angle of 20 degrees.

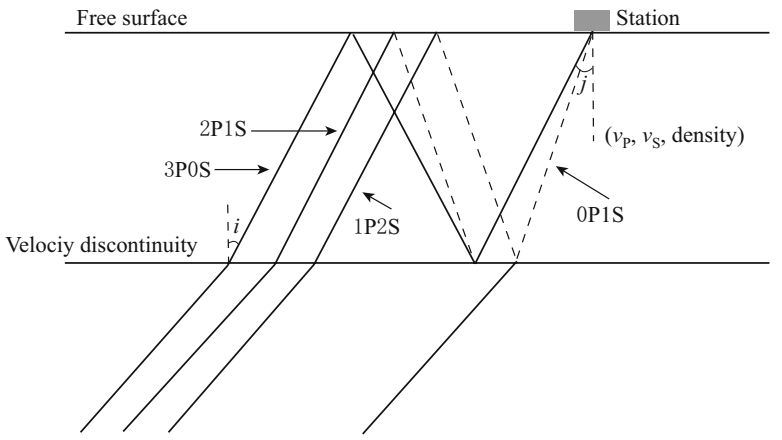

Figure 5 Ray paths of the direct P-wave, P to S converted wave, and the reverberation phases for a onelayer model. $n$ and $m$ in the notation of $n \mathrm{P} m \mathrm{~S}$ are the numbers of $\mathrm{P}$ - and S-wave legs within the layer, respectively. Modified from Niu and James (2002).

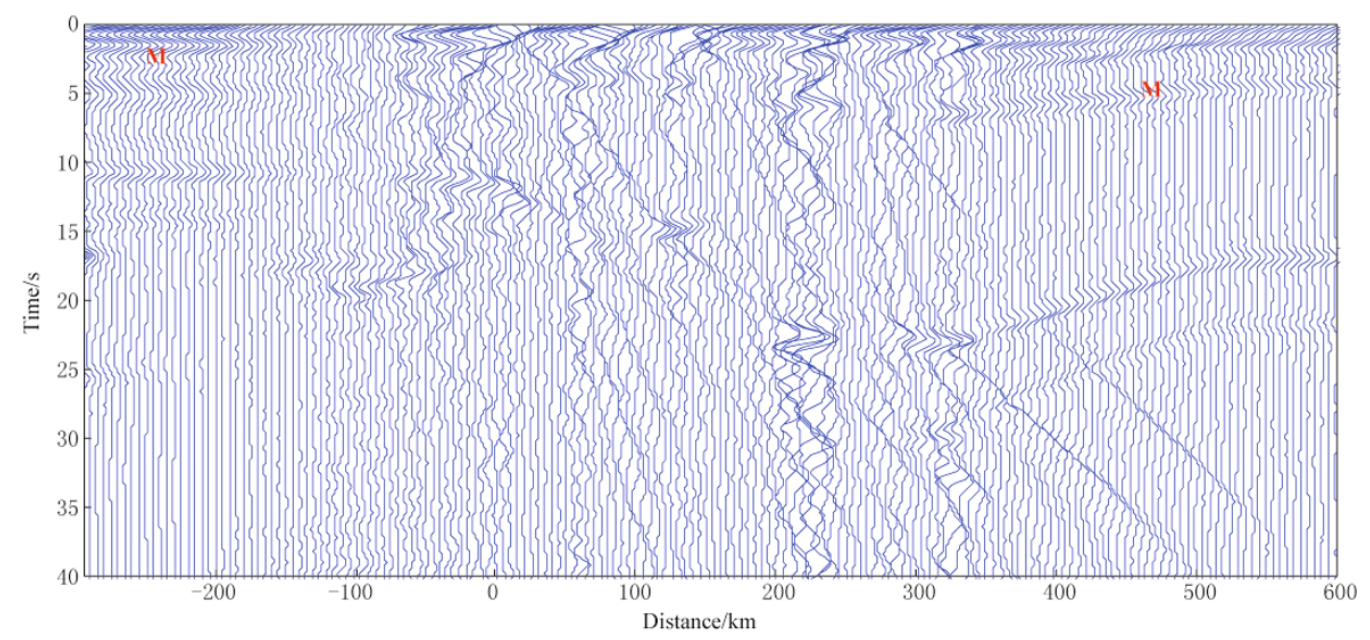

Figure 6 Receiver functions of the event at $20^{\circ}$. "M" marks the conversion from the Moho. 


\section{Common conversion point stac- king}

To convert receiver functions from the time domain to the space domain and enhance the coherent signals, we applied the common conversion point (CCP) stacking method (Dueker and Sheehan, 1997) to the synthetic RFs. Given a velocity contrast beneath the receiver at an arbitrary depth (Figure 5), we can calculate the relative traveltime difference between the direct $\mathrm{P}$ and $\mathrm{P}$-to-S converted waves generated at this contrast based on a $1 \mathrm{D}$ velocity model. Here we took the average of the $2 \mathrm{D}$ models for the simulation as the background model for depth imaging. We then mapped the corresponding amplitude in the receiver function for a given $t_{\mathrm{S}}-t_{\mathrm{P}}$ time difference and repositioned it to its conversion point at depth. Figure 7 shows the $\mathrm{P}$ and $\mathrm{S}$ traveltime tables for the event at $20^{\circ}$, from which we can calculate the traveltime difference between the direct $\mathrm{P}$ wave and $\mathrm{P}$-to-S converted wave. Because seismic rays have finite frequencies, the energy propagates through a tube instead of an infinitesimally thin line, we linearly distribute the amplitude along the Fresnel zone of the conversion point (Figure 8a). Since the depths of the velocity contrasts are unknown, we search the entire model and repeat this process at every depth from the free surface to the depth of source. A receiver function
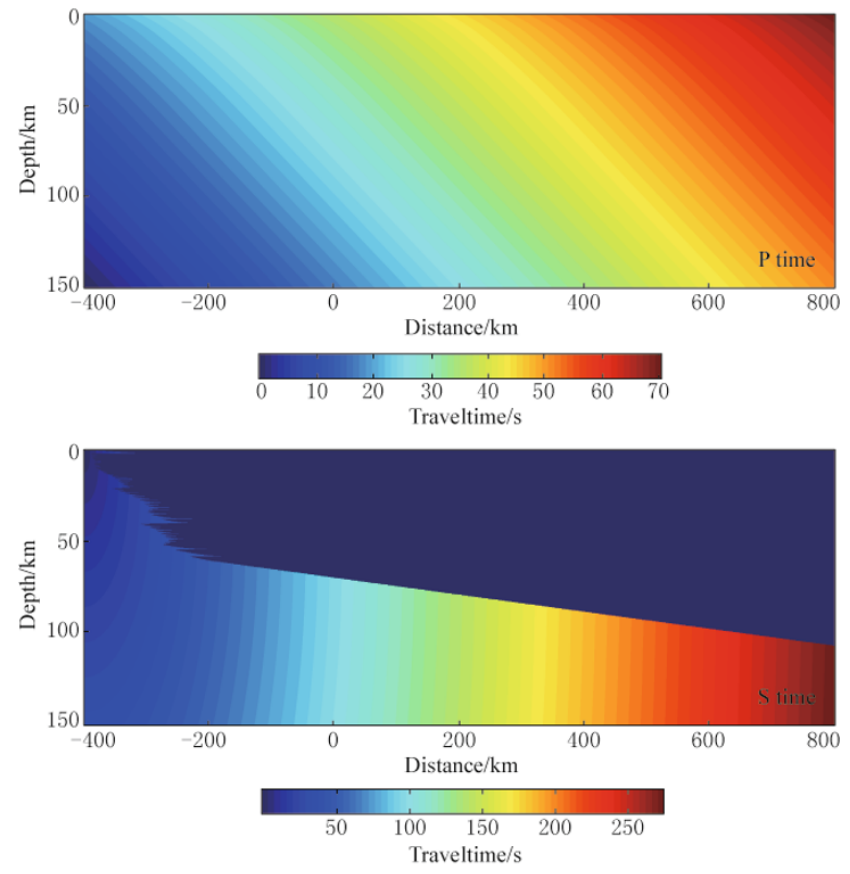

Figure $7 \quad \mathrm{P}$ and $\mathrm{S}$ traveltime tables of the event at $20^{\circ}$ in seconds.
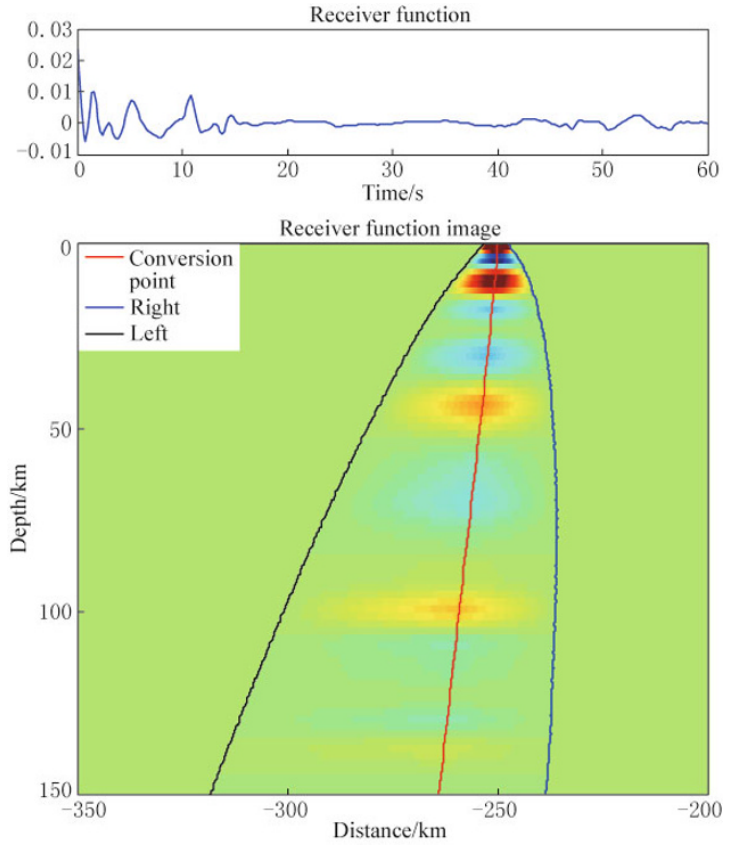

Figure 8 The scheme of the Fresnel zone of a P-wave comes at $20^{\circ}$. A single receiver function before (a) and after repositioning (b). Note that the receiver function becomes a tube increasing in width versus depth. The receiver is located at model coordinate $(-250 \mathrm{~km}, 0 \mathrm{~km})$.

(Figure 8a) then becomes an image tube in space (Figure $8 b$ ). Finally, receiver functions generated from different events and receivers were stacked to obtain a $2 \mathrm{D}$ image, in which the coherent signals can be significantly strengthened, while the incoherent signals cancel each other and do not stand out in the image.

\section{Results and discussion}

We obtained a $1200 \mathrm{~km}(-800 \mathrm{~km}$ to $400 \mathrm{~km}) \times$ $151 \mathrm{~km}(-1 \mathrm{~km}$ to $150 \mathrm{~km})$ 2D image from the CCP stacking (Figure 9). The Moho discontinuity is clearly imaged almost everywhere from $\sim 20 \mathrm{~km}$ depth offshore to $\sim 50 \mathrm{~km}$ depth onshore along the profile, except near the plate bounding strike-slip fault system (model coordinate of $150-180 \mathrm{~km}$ ), where the Moho has the steepest dip. This is because the receiver function method assumes that the velocity discontinuity where the $\mathrm{P}$ wave converts to $\mathrm{S}$ wave is flat (Ammon, 1991). Depth mapping and CCP stacking also requires flat layered structure. The first Moho multiple (2P1S) is also identified at depth of $\sim 3$ times of the primary conversion. Another strong event stands out on the top of the profile at depth $<20 \mathrm{~km}$, which is the bottom of the sedimentary basin. Both Moho and basin bottom events keep 
the shape very well compared to the background model. There exists a very interesting event between the basin bottom and Moho at model coordinate of 150-500 km. This event has the similar shape of basin bottom, same polarity, and $\sim 3$ times of the depth of it, we identify this as the first multiple reflections (2P1S) within basins. By comparing the synthetic RF stack with depth mapped field data (Niu et al., 2007), we suggest that one of the positive events that has been identified as Moho in the field data is actually a reverberation within a sedimentary basin (Figure 9). This misinterpretation was due to the sparseness of the field data, given the passive source station spacing of $\sim 40 \mathrm{~km}$. We will discuss this later with a series of tests.
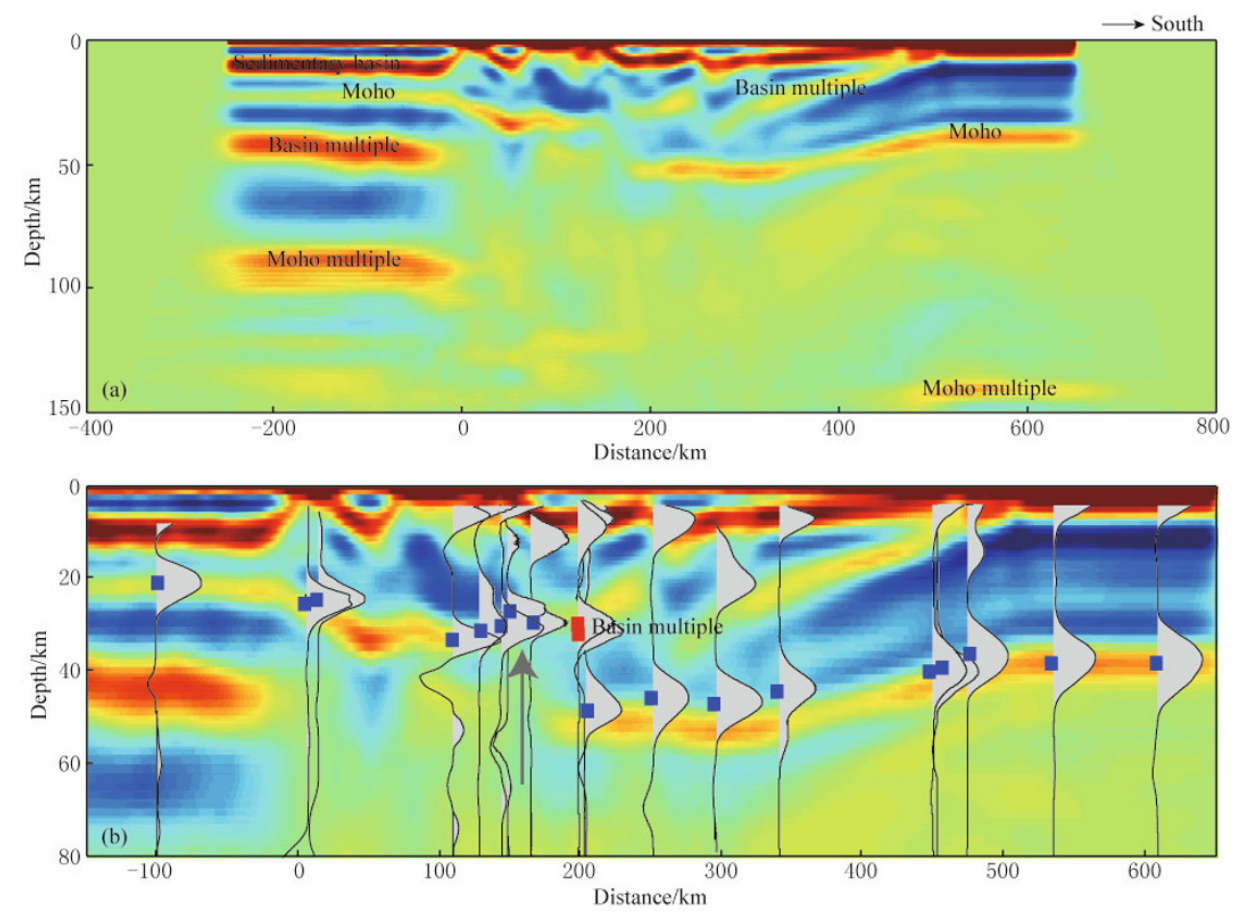

Figure 9 (a) The CCP stacks of six events with input incidence angles of 10, 20, and 30 degrees. Major events (e.g. sedimentary basins, and Moho) and their multiples are labeled. Note that the Moho is not well imaged at model coordinate $\sim 170 \mathrm{~km}$ where it has the steepest dip. (b) Stacks of $20 \mathrm{BB}$ data are superimposed, with good agreement with synthetic data. The blue bars are Moho events determined by field receiver functions, and the red bars are the basin multiples near the plate bounding strike-slip fault system (model coordinate $\sim 150-200 \mathrm{~km}$ ), which have been interpreted as the Moho by the previous receiver function study. The black arrow indicates the plate boundary suggested by the velocity model.

The CCP stacking is moderately sensitive to the background model. To show this we also CCP stacked the synthetic RFs using the IASP91 model as the background (Kennett and Engdahl, 1991), and compared the image with the one using the "average" velocity model taken from the 2D velocity model (Figure 10). Although the shapes of major events are quite similar, the difference of event depths in the two images can be large, e.g. up to $4 \mathrm{~km}$ for the Moho. The average of the active source model gives a better estimate of the Moho depth. In most cases, one can start with a global $1 \mathrm{D}$ reference model, e.g. IASP91, and then correct the traveltimes by adopting a local velocity model to better constrain the event depths (Levander, Personal communication; Zhai and Levander, submitted). Another important feature of the newly stacked image is the existence of the strong event between the basin bottom and the Moho. This event has a shape similar to the basin bottom, a positive polarity, and is $\sim 3$ times the depth of the basin. This test excludes the possibility that discrepancies in Moho depth between the active source and PdS RF field data results from an improper background model.

We next did a resolution test on how reliable CCP stacking is for recovering Earth structure by examining different receiver spacings in the synthetic seismic array. We stacked the receiver functions with station spacings of $10 \mathrm{~km}, 20 \mathrm{~km}$ and $40 \mathrm{~km}$ instead of stacking every single one, and used a Gaussian filter with half-width of the station spacing to smooth the image (Figure 11). We can see that the image of $10 \mathrm{~km}$ spacing can still recover the Moho very clearly, and the image of $20 \mathrm{~km}$ 

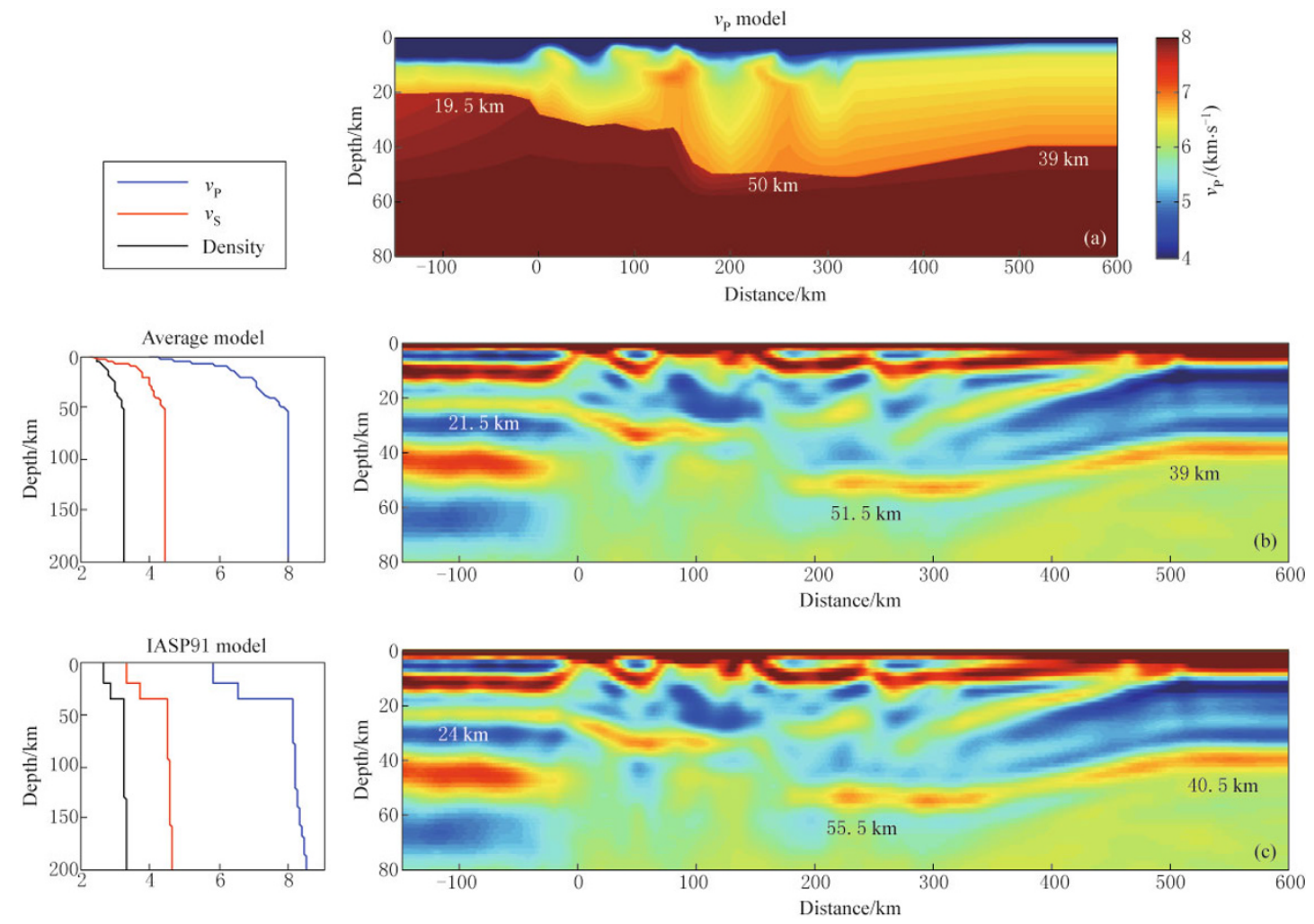

Figure 10 CCP stacks using different background models. (a) The P wave velocity model for FD modeling. (b) CCP stack using the "average" model. (c) CCP stack using IASP91 model. Note that although different background models lead to similar shape of image, the absolute depth of the events are slightly different, e.g. the Moho depth different is up to $4 \mathrm{~km}$. In this study, the "average" model is better than the IASP model, because it gives a more accurate estimate of Moho depth.
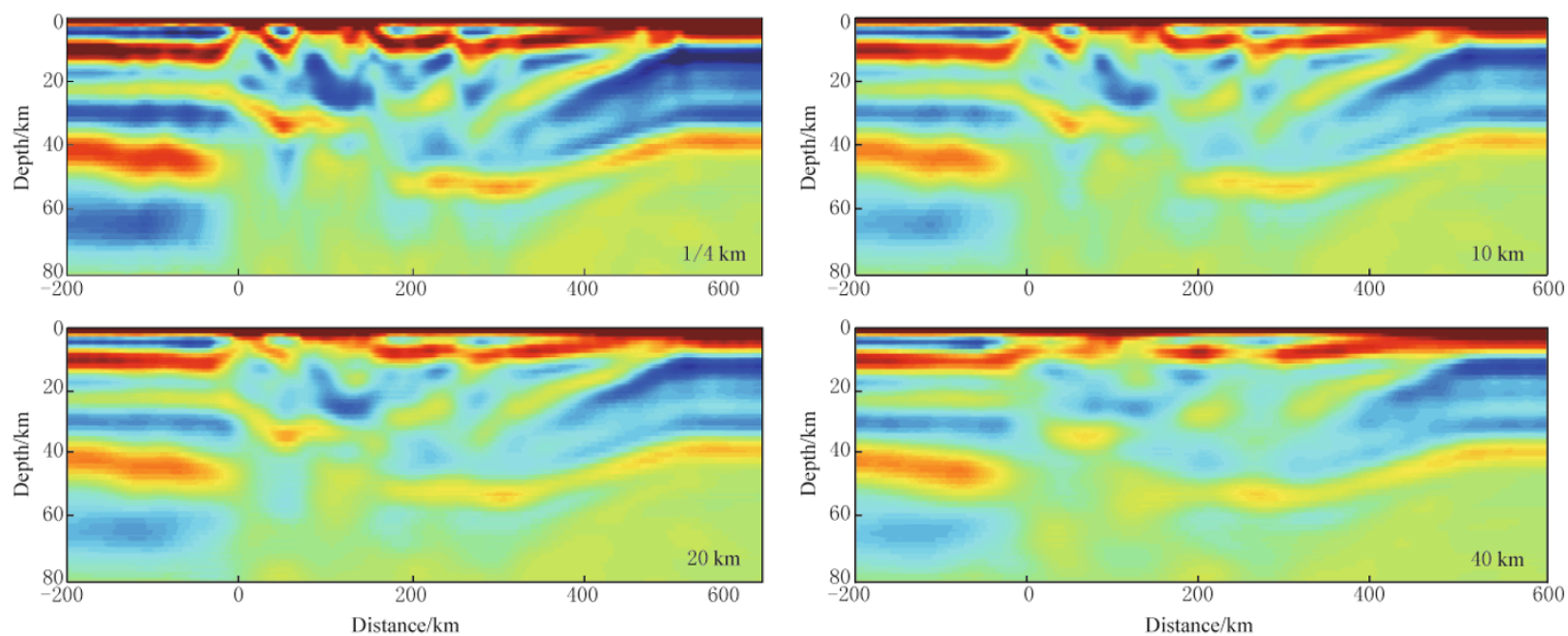

Figure 11 CCP stacks with station spacing of $1 / 4 \mathrm{~km}, 10 \mathrm{~km}, 20 \mathrm{~km}$, and $40 \mathrm{~km}$. Note that the Moho event is getting worse as station spacing is getting greater, particularly $>20 \mathrm{~km}$, although we applied a Gaussian filter with half-width of the station spacing to smooth the image. 
spacing starts to lose some resolution at Moho depth, particularly near the strike-slip plate boundary (model coordinate $\sim 150 \mathrm{~km}$ ), although the Moho in general is still continuous in the profile. In the image of $40 \mathrm{~km}$ spacing, the resolution of the Moho is poor along the entire profile, and it is hard to distinguish the basin multiples from the true Moho event. Therefore, 15-20 km is a proper station spacing to clearly image the Moho in the $64 \mathrm{~W}$ profile, which is about $1 / 2$ of the spacing of the field data. This can explain why the field data failed to determine the Moho depth accurately. Figure 12 shows the Fresnel zone widths of earthquakes at different incident angles. We note that although the associated epicentral distances are within a broad range, the width of the Fresnel zone varies only weakly on the incident angle of the earthquake. At depth of $20 \mathrm{~km}$ (shallowest Moho and most basin multiples in "64W" profile), the Fresnel zone width is $\sim 28 \mathrm{~km}$, about twice of the required station spacing. This means that, to "clearly" image an event, the Fresnel zones of the neighboring receiver functions should overlap each other by $\sim 50 \%$ at the depth of the event, regardless of the epicentral distances. In other words, the station spacing should be about half of the Fresnel zone width at the target depth.

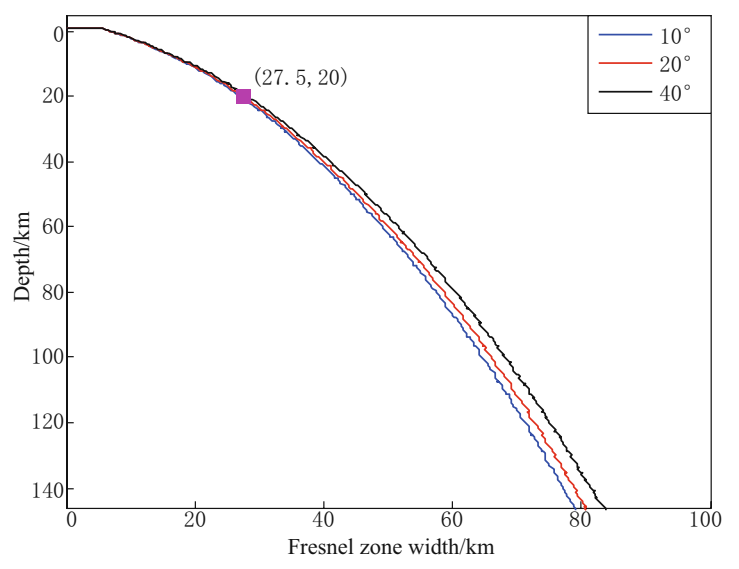

Figure 12 Fresnel zone widths versus depth for three events with incidence angles of 10, 20, and 40 degrees and center period of $0.41 \mathrm{~Hz}$. Note that the Fresnel zone width at $20 \mathrm{~km}$ depth is about $28 \mathrm{~km}$, which means by overlapping Fresnel zone by $50 \%$, the station spacing is required to be about $15-20 \mathrm{~km}$.

\section{Conclusions}

We apply the common conversion point stacking technique to synthetic receiver functions generated by a
2D staggered grid elastic wave finite-difference method to obtain a depth image of the " $64 \mathrm{~W}$ " profile deployed as part of BOLIVAR project. The synthetic CCP stack images the major discontinuities in crust and uppermost mantle very clearly. We also imaged the multiple reflections within sedimentary basins, which were suggested as the Moho discontinuity in the early interpretation to the field data. Our resolution test shows that, to clearly image the Moho in the complicated plate boundary zone, a station spacing of $15-20 \mathrm{~km}$ is required for " $64 \mathrm{~W}$ " profile, as $\sim$ twice dense as the average station spacing of the field data. It is hard to distinguish the basin multiples from the true Moho event using station spacing of $40 \mathrm{~km}$. Depths determined from CCP imaging are sensitive to the background model used. There is up to $4 \mathrm{~km}$ difference based on the "average" model and IASP91 model, although the shapes of major events are quite similar. This test also excludes that the discrepancy of Moho depth was due to the improper background model. We suggest that using a 3D local velocity model to correct the $1 \mathrm{D}$ traveltime might improve the CCP image, which is widely used for recent RF studies.

Acknowledgements We thank Fenglin Niu for the valuable advice, Colin Zelt and Stoney Clark for providing the $\mathrm{P}$ wave velocity model. We also thank our colleagues at Rice University for their advice. This research was supported by NSF grant EAR-0607801.

\section{References}

Ammon C J (1991). The isolation of receiver effects from teleseismic P waveforms. Bull Seismol Soc Am 81: 2504-2 510.

Bezada M J, Magnani M B, Zelt C A, Schmitz M and Levander A (2010). The Caribbean-South American plate boundary at $65^{\circ} \mathrm{W}$ : Results from wide-angle seismic data. J Geophys Res 115: B08402.

Brocher T M (2005). Empirical relations between elastic wavespeeds and density in the earth's crust. Bull Seismol Soc Am 95: 2081-2 092 .

Clark S A, Zelt C A, Magnani M B and Levander A (2008). Characterizing the Caribbean-South American plate boundary at $64^{\circ} \mathrm{W}$ using wide-angle seismic data. $J$ Geophys Res 113: B07401.

Clayton R W and Wiggins R A (1976). Source shape estimation and deconvolution of teleseismic bodywaves. Geophys J Inter 47: 151-177.

Dueker K G and Sheehan A F (1997). Mantle discontinuity structure from midpoint stacks of converted $\mathrm{P}$ to $\mathrm{S}$ waves across the Yellowstone hotspot track. J Geophys Res 102: 8313-8327. 
Kennett B L N and Engdahl E R (1991). Traveltimes for global earthquake location and phase identification. Geophys J Inter 105: 429-465.

Langston C A (1977). The effect of planar dipping structure on source and receiver responses for constant ray parameter. Bull Seismol Soc Am 67: 1029-1 050.

Levander A, Schmitz M, Lallemant H G A, Zelt C A, Sawyer D S, Magnani M B, Mann P, Christeson G, Wright J E, Pavlis G L and Pindell J (2006). Evolution of the Southern Caribbean plate boundary. Eos Trans AGU 87(9): 97-104, doi:10.1029/2006EO090001.

Levander A R (1988). Fourth-order finite-difference P-SV seismograms. Geophysics 53: 1425-1 436.

Ligorria J P and Ammon C J (1999). Iterative deconvolution and receiver-function estimation. Bull Seismol Soc Am 89: 1395-1 400.

Luo Y and Schuster G (1990). Parsimonious staggered grid finite-differencing of the wave equation. Geophys Res Lett 17: $155-158$.

Niu F, Bravo T, Pavlis G, Vernon F, Rendon H, Bezada $M$ and Levander A (2007). Receiver function study of the crustal structure of the southeastern Caribbean plate boundary and Venezuela. J Geophys Res 112: B11308.

Niu F and James D E (2002). Fine structure of the lowermost crust beneath the Kaapvaal craton and its implications for crustal formation and evolution. Earth Planet Sci Lett 200: 121-130.

Niu F, Levander A, Ham S and Obayashi M (2005). Mapping the subducting Pacific slab beneath southwest Japan with Hi-net receiver functions. Earth Planet Sci Lett 239: 9-17.

Owens T J, Zandt G and Taylor S R (1984). Seismic evidence for an ancient rift beneath the Cumberland Plateau, Tennessee: a detailed analysis of broadband teleseismic $\mathrm{P}$ waveforms. J Geophys Res 89: 7783-7 795.

Zelt C A and Smith R B (1992). Seismic traveltime inversion for 2-D crustal velocity structure. Geophys J Inter 108: $16-34$.

Zhu L (2000). Crustal structure across the San Andreas Fault, southern California from teleseismic converted waves. Earth Planet Sci Lett 179: 183-190.

Zhu L and Kanamori H (2000). Moho depth variation in southern California from teleseismic receiver functions. J Geophys Res 105: 2969-2980. 